\title{
Serviço público: significados e sentidos de um trabalho em mutação
}

\author{
Sheila Ataíde Domingues de Souza e Maria das Graças Barbosa Moulin ${ }^{1}$ \\ Universidade Federal do Espírito Santo (Vitória, ES)
}

\begin{abstract}
Neste artigo propomos uma discussão que se situa no campo temático de articulação entre Psicologia e Trabalho. O objetivo foi discutir os sentidos e significados que os servidores públicos atribuem ao trabalho. Para tanto, a análise foi embasada em dados de uma pesquisa de campo com 30 servidores públicos federais que atuam em uma instituição de ensino técnico e tecnológico, e em referenciais teóricos que tratam da centralidade do trabalho e das especificidades dos processos de trabalho no setor de serviços. Os resultados revelam a importância do trabalho na estruturação material e simbólica da vida dos servidores, sendo que os sentidos a ele atribuídos estão relacionados ao provimento da sobrevivência, à (re)produção de valores sociais como autonomia e independência, à integração social, à realização pessoal e sentido existencial. A análise dessa dimensão subjetiva do trabalho também possibilitou dimensionar a importância da atenção à saúde desses trabalhadores em tempos de profundas mudanças no setor público.
\end{abstract}

Palavras-chave: Sentidos do trabalho, Servidores públicos, Centralidade do trabalho, Setor de serviços.

Public Service: meanings and senses of an evolving labor

In this paper we propose a discussion that lies within the thematic field of the articulation between Psychology and Work. The aim was to discuss the meanings and senses that public servants attribute to work. To this end, the analysis was based on data from a field study with 30 federal civil servants who work in an institution of technical and technological education, and on theoretical frameworks that address the centrality of work and the specifics of the work processes in the service sector. The results reveal the importance of work in the structuring of the servants' material and symbolic lives, and that the meanings attributed to it are related to the provision of survival, the (re)production of social values, such as autonomy and independence, social integration, personal fulfillment and existential meaning. The analysis of this subjective dimension of work also allowed the assessment of the importance of caring about these worker's health in these times of deep changes in the public sector.

Keywords: Meanings of work, Public servants, Centrality of work, Services sector.

\section{Apresentação}

"[...] na verdade, a vida da gente acaba girando em torno do trabalho".

(Entrevistado)

Pretendemos, neste artigo, apresentar e discutir os resultados de uma pesquisa de campo realizada junto a servidores públicos, na área temática de articulação entre Psicologia e Trabalho. Constituem foco central da discussão proposta os sentidos que os servidores públicos atribuem ao trabalho, configurando uma reflexão que precedeu o olhar que depositamos sobre a saúde desses servidores e que, em conjunto, resultou na dissertação de mestrado de uma das autoras. ${ }^{2}$

Ao tratar da articulação entre Psicologia e Trabalho, buscaremos trazer à discussão dois elementos: o primeiro, de ordem teórico-metodológica, refere-se à subjetividade do trabalhador compreendida a partir de uma perspectiva que atribui relevância às capacidades desses sujeitos não apenas no que tange à sua contribuição para a produção de bens e serviços, mas sobretudo para a construção e transformação da realidade social. Nessa abordagem, importam os aspectos

1 Departamento de Psicologia Social e do Desenvolvimento, Programa de Pós-Graduação em Psicologia, Universidade Federal do Espírito Santo.

2 Dissertação de mestrado intitulada Transformações do trabalho no serviço público: o caso dos técnicos em educação do Instituto Federal de Educação, Ciência e Tecnologia do Espírito Santo, defendida por Sheila Ataíde Domingues de Souza, no Programa de Pós-Graduação em Psicologia, da Universidade Federal do Espírito Santo, sob a orientação da Profa. Dra. Maria das Graças Barbosa Moulin. 
subjetivos relacionados ao trabalho e ao trabalhar, entendidos a partir de sua contribuição para a constituição do "ser" trabalhador. O segundo elemento a que visamos pôr em destaque, relaciona-se à categoria de sujeitos investigados - os servidores públicos. De modo geral, os estudos voltados à saúde dos trabalhadores do setor serviço começaram a ganhar corpo nas duas últimas décadas, ampliando-se os tipos de ocupações investigadas. Dentre as categorias profissionais tradicionalmente mais estudadas, encontram-se os trabalhadores da informática, profissionais da saúde e bancários (Lacaz \& Minayo-Gomez, 2005). No que diz respeito à situação de trabalho dos servidores públicos, apresentaremos, posteriormente, algumas pesquisas realizadas.

Como já sinalizaram Pena e Minayo-Gomez (2010), os estudos mais recentes no campo da Saúde do Trabalhador, embora considerem as expressivas transformações na organização do trabalho resultantes da reestruturação produtiva, ainda não se aprofundaram suficientemente sobre as especificidades do setor serviço e sua relação com a saúde e a subjetividade dos trabalhadores que atuam nesse segmento.

Desse modo, em uma incursão aos aspectos do trabalho que singularizam o setor serviço, cabe questionar: Quais sentidos os servidores públicos atribuem ao trabalho? Quais valores ou significados socialmente produzidos permeiam os sentidos do trabalho para esses trabalhadores? A partir da visibilidade desses elementos, que perspectivas podemos traçar para a saúde e o bem-estar dos trabalhadores que atuam nesse segmento face às mudanças que vêm sendo implementadas na organização do trabalho no setor público?

A fim de circunstanciar esses questionamentos discutiremos algumas particularidades do setor serviço com enfoque no serviço público, e em seguida, buscaremos uma articulação com a questão da centralidade e dos sentidos do trabalho. Na sequência, apresentaremos os resultados coletados a partir de entrevistas com servidores públicos atuantes em uma instituição pública federal de ensino.

\section{Um olhar sobre o serviço público}

Os processos de trabalho no serviço público se caracterizam por atividades típicas do setor terciário ou de serviços. Conforme revisão de Meirelles (2006), os estudos de Fischer (1939) e Clark (1940) reuniram, pioneiramente, sob a denominação de setor terciário, diversas atividades de grande expressão na composição do produto interno bruto. Desde então, vários esforços teóricos e metodológicos têm sido empreendidos no intuito de compreender as particularidades e especificidades desse setor. Contudo, conforme Pena e Minayo-Gomes (2010, p. 373), mesmo na economia atual, "[o setor] tem uma acepção ainda indefinida e reúne uma grande diversidade de atividades, produtos e processos".

Contrariamente ao setor industrial, cuja expressão foi ampliada a partir de uma revolução histórica, a origem do setor serviço está ligada à arrecadação e à administração de tributos pelo Estado (Pena \& Minayo-Gomes, 2010). Na economia clássica, na figura de Smith (1776, citado por Meirelles, 2006), as atividades de serviço são compreendidas como trabalho improdutivo e de baixa rentabilidade, cujo resultado são produtos intangíveis. Nessa perspectiva, trata-se de atividades "incapazes de gerar lucros suficientes para a sua manutenção e expansão. Por isso mesmo, grande parte destas atividades é realizada pelo governo, financiada a partir de taxas e impostos cobrados pelas autoridades públicas" (Meirelles, 2006, p. 121).

Em outra concepção, Marx (1867, citado por Meirelles, 2006) compreende que todos os serviços cujo processo produtivo se dê em bases capitalistas de produção são considerados produtivos, independentemente de o resultado ser tangível ou intangível, pois se entende que "a relação de compra e venda não é uma relação entre objetos e coisas, e sim uma relação social. Nesta perspectiva, a definição de trabalho produtivo se dá de forma independente do conteúdo material e tangível da mercadoria" (Meirelles, 2006, p.122). 
$\mathrm{Na}$ caracterização do setor, entre os autores pesquisados por Meirelles (2006), destaca-se o conceito de simultaneidade, segundo o qual a produção do serviço ocorre no momento em que ele é consumido. Essa característica traz outros desdobramentos - uma vez que não podem ser estocados, acumulados, os serviços também assumem um caráter intangível, assim como se torna mais difícil comensurar sua produção. Ao mesmo tempo, trata-se de processos produtivos que asseguram uma relação mais direta entre trabalhadores e consumidores/usuários, por meio da qual se constituem, conforme o grau de aproximação entre as duas partes, relações de coprodução (Pena \& Minayo-Gomes, 2010).

O que se percebe é que as atividades do setor serviço são intensas em interações humanas, e que essas, como afirmaram Assunção e Lima (2010), não se restringem aos momentos de efetivo face a face entre trabalhadores e usuários, pois os conteúdos das demandas dos usuários produzem efeitos para a subjetividade dos trabalhadores (seus modos de pensar, agir, seus afetos) que se estendem para aquém e além desses encontros.

Ainda que consideremos que todo trabalho envolve, em alguma medida, tanto aspectos afetivos como cognitivos, a interação intensiva entre trabalhadores e usuários no setor de serviços gera, de acordo com Assunção e Lima (2010), uma exigência latente de administração dos afetos. Segundo estes autores, "denominam-se exigências afetivas as requisições e as modulações da subjetividade dos indivíduos no âmbito da atividade de trabalho". Tais autores observam que

No setor de serviços, os problemas físicos classicamente associados à racionalização taylorista e ao trabalho repetitivo somam-se às questões de natureza emocional, as quais são relacionadas ao conteúdo do trabalho, às circunstâncias materiais e organizacionais em que se desenrola a prestação de serviços e às relações intersubjetivas pelas quais se efetiva a relação de serviço (Assunção \& Lima, 2010, p. 210).

Os desdobramentos relacionados a essa forma intensiva de interação entre trabalhadores e usuários no serviço público caracterizam um aspecto do trabalho nesse setor que precisa ser mais bem investigado.

Em uma perspectiva histórica, percebe-se que as mudanças nos processos de produção e na organização do trabalho desde a reestruturação produtiva também alcançaram o setor público. Chanlat (2002) propõe uma reflexão que articula a adoção do gerencialismo no serviço público e uma importante especificidade desse setor - sua ética. Apesar das críticas sobre os antigos modelos de administração pública de inspiração weberiana, a organização burocrática do trabalho se apoia na ética do bem comum. Conforme este autor (2002, p. 6),

[...] a introdução de formas empresárias de gestão no sistema público talvez seja uma ameaça a essa separação das ordens de existência, já que doravante todas as esferas serão reguladas pelo mesmo éthos, o dos negócios. O funcionário, caução tradicional do interesse geral e do bem comum, deverá de agora em diante obedecer às exigências dos clientes, até mesmo do seu chefe imediato, como acontece segundo a pesquisa realizada por Robert Jackall, nas empresas americanas (1998). A imparcialidade, o tratamento igualitário e o interesse geral correm o risco de desaparecer a longo prazo em benefício de mecanismos cada vez mais mercantis.

Nesse mesmo sentido, Lancman, Sznelwar, Uchida e Tuacek (2007) acrescentam que na interação com os usuários, os servidores exercem a tarefa de intermediação entre o Estado e os cidadãos, com consequências que precisam ser consideradas. Apoiados no pensamento de Arendt (2005), Lancman et al. (2007, p. 83) assim expressam: 
O servidor público acaba intermediando as esferas do público e privado numa sociedade onde os interesses individuais, por vezes, se sobrepõem aos interesses coletivos. Cabe às esferas públicas e, sobretudo, aos trabalhadores que as representam e que estão em contato direto com os cidadãos, sofrer o impacto das deficiências do Estado no contato com a população e fazer valer o interesse da comunidade numa sociedade onde o cidadão comum espera privilégios e satisfação de suas necessidades pessoais.

O gerenciamento dos conflitos que se originam nessa tarefa de mediação, caracterizada pelos autores supracitados, faz parte do dia a dia de trabalho de boa parte dos servidores públicos, e demandam considerável mobilização subjetiva, que também constituem os processos de trabalho no setor público.

No plano simbólico, consideramos que as representações sobre o serviço público, e por extensão, sobre seus servidores, em especial aquelas que se construíram a partir do governo Collor na década de 1990, levaram à construção de uma imagem negativa do servidor público³, contribuindo para o estabelecimento de um cenário de precarização das relações de trabalho no setor público com impactos também pouco investigados para os servidores.

A imagem do servidor público foi alvo de interesse nos estudos realizados por França (1993) e Ferri (2003). Ambos retratam um conjunto de estereótipos negativos historicamente associados à imagem do servidor público, em que este é caracterizado como trabalhador que não trabalha, ineficiente, incompetente, desestimulado, improdutivo, acomodado, relapso, faltoso, moroso, e que presta mau atendimento.

Considerando que o valor social atribuído ao trabalho repercute na autoestima do trabalhador, entendemos que essa análise também contribui para a reflexão sobre a relação que se estabelece entre os processos de trabalho que se desenvolvem no serviço público e a subjetividade dos servidores, como também se faz relevante para compreender a forma como esses indivíduos significam seu trabalho e se produzem como sujeitos.

\section{Centralidade e sentidos do trabalho}

A discussão sobre "sentidos do trabalho" não pode prescindir de considerar o aspecto central ocupado pelo trabalho na vida dos sujeitos. É nessa perspectiva que os sentidos atribuídos ao trabalho assumem sua real dimensão.

Os estudos que se ocupam da discussão acerca da centralidade do trabalho, questionam se a atual conjuntura socioeconômica permitiria sustentar que o trabalho se mantém como elemento estruturante da vida e da sociedade, em conformidade com princípios marxistas.

Compreendemos, com Antunes e Alves (2004), que o trabalho continua a exercer um papel central na estruturação social, e também compartilhamos com Borsoi (2007, p. 107) o entendimento de que

Se nossa humanidade só é possível a partir da singularidade do mundo dos afetos e do mundo do trabalho, então é necessário o reconhecimento prático do trabalho como dotado também de significado especial na vida das pessoas que dele vivem.

3 O então candidato à presidência Fernando Collor de Mello pautou sua campanha eleitoral em 1989 na caça aos "marajás”, em alusão a servidores públicos que perceberiam salários excessivamente altos. Não tardou que o conjunto dos servidores públicos fossem todos identificados como marajás, independentemente do valor do salário ou do trabalho executado. 
Ao longo do tempo o trabalho foi assumindo formas específicas de execução e de organização, adquirindo cada vez mais complexidade e tecnicidade, em especial a partir da Revolução Industrial e da expansão do capitalismo, quando se tornou, para além de ocupação básica do homem, um fator de produção (Krawulski, 1998). Na condição de objeto histórico (Gondar, 1989), o trabalho teve seus valores e significados forjados e transformados pelos homens em conformidade com os arranjos sociais, políticos, econômicos e culturais constituídos no decurso do tempo.

Entre os antigos gregos, atividades manuais que hoje entendemos como trabalho eram destituídas de qualquer prestígio social. Já ao longo da Idade Média, com a expansão do cristianismo e a instauração da ordem monástica, o trabalho foi adquirindo valor moral, à medida que se tornava meio de elevação espiritual e servia à reconstrução das cidades destruídas pela queda do Império Romano.

Com a emergência da classe burguesa, decorrente da prosperidade, do avanço das técnicas de produção, e do acúmulo de riquezas, o trabalho se revestia de novo sentido; sua finalidade encontrava-se associada à supremacia da razão sobre o divino. Abandonando o propósito de culto ou salvação, o trabalho, ainda assim, conservava um sentido moral, uma vez que o poder de intervir sobre a natureza e dominá-la tornava-se parte da essência humana. Instauravam-se, desse modo, as condições que faziam do trabalho um imperativo, consolidado nas sociedades capitalistas até os dias atuais (Gondar, 1989).

Ao longo do século XX, a perspectiva racionalista dos sistemas fordista e taylorista de produção, baseada na expropriação do saber operário, levou à fragmentação das tarefas, ao controle estrito do tempo gasto nas mesmas, e ao uso da tecnologia para imprimir ritmos cada vez mais intensos e acelerados de trabalho, gerando um universo de trabalho monótono e extenuante, no qual a autonomia do trabalhador é restrita ao extremo.

Esse modo de organizar o trabalho trazia um grande desgaste para o trabalhador - além de explorar ao máximo a força física, restringia as possibilidades de participação subjetiva - de fazer uso da inteligência e da criatividade no planejamento e organização das tarefas.

A crise financeira dos anos 1970 gerou um período de grande instabilidade do mercado, acirrou a competitividade entre as empresas, levou à busca pela redução de custos na produção e pela melhoria da qualidade dos produtos e serviços. Por conseguinte, a classe trabalhadora encontrava-se esgotada frente a um "trabalho puramente mecanizado, rotinizado, gerador de altos índices de absenteísmo, paralisações e sabotagens” (Navarro \& Padilha, 2007, p. 17).

Esse novo cenário exigiu transformações que levaram ao surgimento de modelos alternativos de produção, com vistas à manutenção do sistema capitalista. Merece destaque a introdução dos modelos de organização flexível, como o sueco, o italiano, e em especial, o japonês (toyotismo), que segundo Pinto (2007, p. 72)

superou em produtividade todos os demais sistemas de organização flexível [...], sobretudo, por não buscar eliminar ou minimizar o confronto entre a classe trabalhadora e o empresariado nos locais de trabalho, mas sim, por aproveitar-se dessa situação e, através da manipulação da subjetividade dos trabalhadores, extrair-lhes o acúmulo de conhecimentos tácitos que adquirem, a favor da acumulação capitalista.

O toyotismo tentou resgatar o nexo entre concepção e execução do trabalho por meio da convocação ao trabalhador do uso da sua criatividade e inteligência no interesse do capital. Através de vários mecanismos de recompensa (prestígio, ascensão funcional, premiações), as organizações atuais têm procedido a uma verdadeira "gestão dos afetos", na qual o orgulho, a vaidade e, sobretudo, a competitividade são manipulados a fim de se obter o investimento subjetivo na organização (Antunes \& Alves, 2004; Seligmann-Silva, 2011). 
Se o trabalho conserva seu papel central na estruturação social, constituindo-se como importante fonte de significação da vida e exercendo grande influência na constituição da subjetividade, Antunes e Alves (2004) alertam sobre a necessidade de considerar as profundas mutações pelas quais passou o mundo do trabalho ao longo da mundialização do capital, em especial o processo de complexificação, heterogeneização e fragmentação.

Tais autores supracitados destacam a redução da antiga classe trabalhadora composta de trabalhadores manuais, fabris, industriais, especializados, e o acréscimo dos trabalhadores informais, terceirizados, subcontratados, dos vínculos part-time, ou temporários. Da mesma forma, houve uma expansão da inserção das mulheres no mercado de trabalho, sobretudo em condições de trabalho precarizado, desregulamentado, ou ainda, em domicílio. Vê-se, também, a inclusão criminosa de crianças no mercado de trabalho, enquanto para os jovens em idade pós-escolar, tem se tornado cada vez mais difícil sua inserção, restando-lhes muitas vezes, como alternativa ao desemprego, o trabalho precarizado. A reinserção de adultos acima de 40 anos ou de idosos no mercado de trabalho mostra-se bastante difícil, uma vez que as atuais tendências priorizam o trabalhador polivalente, preparado para múltiplas funções, em detrimento daqueles fortemente especializados. Face à crise do emprego, dá-se a ampliação do Terceiro Setor como forma alternativa de ocupação. Os processos produtivos têm suas fronteiras ampliadas, alcançando espaços transnacionais. A nova classe trabalhadora inclui ainda os trabalhadores assalariados das regiões agroindustriais, assim como os desempregados (Antunes \& Alves, 2004).

As críticas relativas aos modos de trabalho próprios do capitalismo atual assinalam a diferença entre dois tipos de trabalho: um, que se inscreve como via de acesso a algo que se estende para além da própria subsistência - a sociabilidade e a constituição da própria subjetividade; e outro, que está atrelado muito mais ao valor de troca do que ao valor de $\mathrm{uso}^{4}$ daquilo que produz, provocando o estranhamento do trabalhador frente ao que é produzido, não podendo mais este se reconhecer naquilo que produz (Navarro \& Padilha, 2007, p. 15).

Ainda assim, quando tratamos da questão da centralidade do trabalho, compreendemos, com Navarro e Padilha (2007, p. 14), que "as pessoas, apesar de as transformações que testemunhamos hoje, continuam ancorando sua existência na atividade laboral, mesmo aquelas que se encontram em situação de desemprego", ou que estão submetidas a processos de trabalho extremamente precarizados. Além disso, as autoras ainda salientam que:

A centralidade do trabalho dá-se não só na esfera econômica (o trabalho é a fonte de renda da maioria da população mundial) como também na esfera psíquica - o que, certamente, representa um paradoxo, uma vez que a atividade laboral ainda parece ser uma importante fonte de saúde psíquica (tanto que sua ausência, pelo desemprego ou pela aposentadoria, é causa de abalos psíquicos) ao mesmo tempo em que se registram cada vez mais pesquisas que evidenciam o trabalho como causa de doenças físicas, mentais e de mortes (Navarro \& Padilha, 2007, p. 15).

A análise do trabalho a partir nessa perspectiva histórica, considerando os diferentes contextos nos quais se produzem seus sentidos, nos permite, assim, reafirmar sua centralidade na estruturação social, compreendendo que sua importância não se restringe à garantia da sobrevivência material,

4 Tomamos aqui os conceitos marxistas de "valor de uso" e "valor de troca". Segundo Marx (1996, p. 166 ), "A utilidade de uma coisa faz dela um valor de uso. [...] O valor de uso realiza-se somente no uso ou no consumo. Os valores de uso constituem o conteúdo material da riqueza, qualquer que seja a forma social desta" [...] "O valor de troca aparece, de início, como a relação quantitativa, a proporção na qual valores de uso de uma espécie se trocam contra valores de uso de outra espécie, uma relação que muda constantemente no tempo e no espaço". Ainda conforme tal autor, a relação de troca das mercadorias é caracterizada pela abstração de seus valores de uso. Então, "ao desaparecer o caráter útil dos produtos do trabalho, desaparece o caráter útil dos trabalhos neles representados, e desaparecem também, portanto, as diferentes formas concretas desses trabalhos, que deixam de diferenciar-se um do outro para reduzir-se em sua totalidade a igual trabalho humano, a trabalho humano abstrato" (Marx, 1996, p. 166). 
mas se estende a outras dimensões da vida dos sujeitos, como sua integração social e a constituição de suas subjetividades, da qual participa a atribuição de sentidos.

No âmbito da Psicologia contemporânea, a revisão de literatura, realizada por Tolfo, Coutinho, Baasch e Cugnier (2011), identificou as seguintes vertentes teóricas que fundamentam as pesquisas sobre sentidos e significados do trabalho: cognitivista, existencialista, construcionista, de estudos culturais e sócio-histórica.

Em uma aproximação à perspectiva da psicologia sócio-histórica, compreendemos que a atribuição de significados ou sentidos é parte de um mesmo processo pelo qual o homem transforma o mundo e se constitui como humano. Desse modo, a significação "é a atividade mais geral e fundamental do ser humano, a que diferencia em primeiro lugar o homem dos animais do ponto de vista psicológico" (Vygotsky, 1995, p. 84)

Também entendemos, com Dejours (2008, p. 84), que "a análise da dimensão subjetiva do trabalho, ou a 'objetivação da subjetividade', passa, necessariamente, pelo acesso ao sentido que aquela situação tem para os próprios indivíduos".

Embora pertençam a diferentes matrizes teóricas, encontramos convergências nas ideias dos autores supracitados: reafirmam a centralidade do trabalho; compreendem-no como categoria histórica; atribuem relevância às condições objetivas ou concretas de sua realização; e reconhecem sua importância para a construção da identidade. ${ }^{6}$

No intuito de clarificar a expressão "sentido do trabalho", recorremos a uma revisão realizada por Tolfo e Piccinini (2007) - segundo estas autoras, dentre os estudos que buscam compreender os "sentidos" e/ou os "significados" do trabalho, muitos utilizam os dois termos como sinônimos. Contudo, embora elas também ressaltem a "inequívoca interdependência” entre os dois termos, propõem uma distinção entre os mesmos, que adotamos neste estudo:

Os significados são construídos coletivamente em um determinado contexto histórico, econômico e social concreto, ao passo que os sentidos são caracterizados por ser uma produção pessoal em função da apreensão individual dos significados coletivos, nas experiências do cotidiano. Sendo que essas transformações que os sentidos e significados sofrem, são construídos por meio de uma relação dialética com a realidade (Tolfo \& Piccinini, 2007, p. 44).

Dentre os estudos empíricos sobre sentidos e significados do trabalho realizados no Brasil, encontra-se a pesquisa realizada por Morin, Tonelli e Pliopas (2007) junto a jovens executivos brasileiros, que indicou três dimensões dos sentidos atribuídos pelos sujeitos, nos quais se destacaram temas recorrentes: dimensão individual (satisfação pessoal; independência e sobrevivência; crescimento e aprendizagem; e identidade); dimensão organizacional (utilidade; relacionamento; e inserção social); e dimensão social (contribuição social).

Alguns desses temas também são referidos na pesquisa desenvolvida por Martins e Krawulski (2012), que investigaram o cotidiano de trabalho de servidores públicos que atuam na área da saúde. Conforme estas autoras, os sentidos do trabalho identificados na pesquisa estavam associados tanto a dimensões mais particulares determinantes das trajetórias profissionais dos sujeitos - formação pessoal, criação familiar, condicionamento pessoal, profissão, sobrevivência, emprego, fonte de renda e realização pessoal; como a valores humanos/genéricos relacionados ao serviço no setor público - acreditar no trabalho no serviço público e a possibilidade de devolver à sociedade o investimento realizado na formação universitária (Martins \& Krawulski, 2012).

5 Tradução nossa.

6 Sobre a centralidade do trabalho em Dejours, e demais aspectos relacionados, ver Franco (2004). 
Coutinho, Diogo e Joaquim (2008) investigaram os sentidos do trabalho para servidores públicos da área de manutenção de uma universidade, e identificaram que os sentidos atribuídos ao trabalho pelos participantes possuíam, de modo geral, uma conotação positiva, associada ao sentimento de realização e felicidade, e estavam relacionados à possibilidade de sustento pessoal e familiar oferecida pelo trabalho, à importância da estabilidade no emprego (característica do setor público), à sua centralidade na vida dos sujeitos, e à reafirmação da identidade a partir do sentimento de contribuição social. Dentre as frustrações e decepções relatadas pelos sujeitos, tais autoras identificaram a ausência de reconhecimento, a invisibilidade do trabalho ou sua expressão pelo "negativo", pois o trabalho daqueles servidores é demandado à medida que algo dá errado, ou quando surge um problema.

Nascimento e Oliveira (2013) pesquisaram os sentidos do trabalho para servidores públicos técnico-administrativos de uma universidade, considerando as diferenças entre duas gerações de servidores, uma constituída por aqueles que ingressaram antes da reforma da administração pública, na década de 1990, e outra de jovens servidores cujas carreiras profissionais tiveram início com a retomada dos concursos públicos no governo Lula, e ao mesmo tempo, em um contexto sociocultural de forte determinação dos princípios neoliberais. Tais autores identificaram que nos dois grupos de servidores o trabalho exerce um papel estruturante da vida, contudo, observaram diferenças significativas relativas aos modos de subjetivação e atribuição de sentidos ao trabalho, para cada um deles, considerando as diferenças contextuais em que se efetivaram. Dentre outras diferenças, para os servidores mais antigos os sentidos do trabalho associam-se a uma perspectiva mais subjetiva, de valorização dos vínculos interpessoais construídos ao longo da vida profissional, enquanto para os mais jovens predomina uma perspectiva instrumental, fundada na lógica do consumo, na qual o trabalho deve servir a propósitos objetivos, que além da subsistência, devem assegurar o alcance dos bens de consumo que julgam importantes a sua qualidade de vida.

A partir das considerações e dos estudos apresentados, objetivamos, neste estudo, refletir sobre os sentidos atribuídos ao trabalho por servidores públicos técnico-administrativos que atuam em uma instituição pública federal de ensino, localizada no Estado do Espírito Santo.

A instituição pesquisada ocupa um lugar de grande destaque no cenário da educação profissional no Estado, e possui amplo prestígio e reconhecimento social, que de certo modo, e conforme o senso comum, caracteriza-a como uma oportunidade privilegiada de exercício profissional. Ao longo das duas últimas décadas, essa Instituição vem atravessando profundas transformações, em um processo de acelerada expansão de sua estrutura física e de serviços, assim como de aumento e diversificação da clientela atendida.

\section{Método}

A análise dos sentidos atribuídos ao trabalho envolveu uma articulação entre trabalho e subjetividade na qual o trabalho foi considerado para além de sua dimensão técnico-produtiva, e compreendido por sua relevância como fonte de significação e estruturação da vida. Essa tarefa demandou a utilização de uma abordagem qualitativa em pesquisa, que, de acordo com Minayo (2010), se revela mais apropriada à investigação dos fenômenos humanos que constituem a realidade social, à medida que permite alcançar "o universo dos significados, dos motivos, das aspirações, das crenças, dos valores e das atitudes" (Minayo, 2010, p. 21). Além disso, o estudo assumiu um caráter exploratório, uma vez que buscou respostas para lacunas ainda existentes na literatura científica referente à temática em questão.

Em um dos campi de uma instituição pública federal de ensino técnico e tecnológico, situada no Estado do Espírito Santo foi realizada uma pesquisa de campo, no qual foram recolhidos os dados por meio de entrevistas individuais, com roteiro semiestruturado. A entrevista, enquanto 
forma privilegiada de interação social, possibilitou o acesso aos "dados subjetivos", que "só podem ser conseguidos com a contribuição da pessoa" (Minayo, 2010, p. 64).

A Instituição pesquisada foi selecionada por sua representatividade no cenário estadual das organizações públicas, e pela facilidade de acesso da pesquisadora. À época da coleta de dados, o campus contava com 221 servidores técnico-administrativos em seu quadro de pessoal. Elegemos, por conveniência, direcionar o estudo para os servidores que desempenham atividades diretamente relacionadas ao ensino, que na ocasião da coleta de dados, perfaziam um total de 55 servidores.

A definição do quantitativo de participantes se deu por inclusão progressiva, e foi interrompida pelo critério da saturação, "quando as concepções, explicações e sentidos atribuídos pelos sujeitos [começaram] a ter uma regularidade de apresentação" (Deslandes, 2010, p. 48). Sendo assim, foram totalizadas entrevistas com trinta servidores.

Dentre os entrevistados, havia sete homens e vinte e três mulheres com idades entre 26 e 68 anos. Quanto à escolaridade, o grupo mostrou alto nível de qualificação: a maioria (25) possui nível superior de ensino, sendo que vinte e um deles já realizaram pós-graduação; quatro possuem o ensino médio e somente um participante tem ensino fundamental. Em relação ao tempo de serviço na Instituição, sete participantes possuem entre vinte e dois e trinta e oito anos de serviço; nove possuem entre doze e vinte e um anos; e quatorze deles tem entre um e seis anos de ingresso na Instituição.

Os participantes ocupavam cargos técnicos diversos (assistente social, pedagogo, psicólogo, auxiliar/assistente administrativo, bibliotecário, vigilante, técnico em assuntos educacionais), sendo que quatro deles ocupavam cargos de chefia. Um aspecto comum a todos os participantes é o fato de prestarem atendimento ao público interno e externo à Instituição, o que os mantêm em contato direto com alunos, professores e comunidade externa; e de contribuírem para a execução das políticas de ensino adotadas pela Instituição.

Os potenciais participantes foram contactados e informados sobre as condições de participação na pesquisa, que asseguraram o anonimato sobre as informações prestadas, e o atendimento aos preceitos éticos estabelecidos pela Resolução CNS 196/96 para realização de pesquisas envolvendo seres humanos. ${ }^{7}$ Aos trabalhadores que concordaram em participar, foi destinado um Termo de Consentimento Livre e Esclarecido, assinado por ambas as partes (pesquisadora e pesquisado). Todas as entrevistas foram gravadas e transcritas na íntegra.

A análise dos dados foi pautada no Método de Interpretação dos Sentidos, que compreende três etapas sucessivas de análise: inicia-se com uma leitura compreensiva do material recolhido, na qual se busca tanto uma visão do conjunto como a identificação das particularidades; em seguida procede-se a uma exploração do material para além dos fatos e relatos dos participantes, buscando identificar ideias explícitas e implícitas, que passam então a ser problematizadas e articuladas com sentidos socioculturais mais amplos que lhes são atribuídos; e, por fim, elabora-se uma síntese interpretativa, que procura estabelecer um diálogo entre as ideias problematizadas, o referencial teórico adotado e as informações provenientes de outros estudos acerca do assunto (Gomes, 2010).

\section{Resultados e discussão}

Os sentidos do trabalho enunciados nos relatos dos entrevistados, tal como aqueles encontrados em estudos com outras categorias profissionais possuem múltiplas facetas ${ }^{8}$, que se

7 A pesquisa foi aprovada pelo Comitê de Ética em Pesquisa da Universidade Federal do Espírito Santo, sob registro $n^{\circ} 175 / 11$.

8 A exemplo dos estudos realizados por Dal Magro e Coutinho (2008) - trabalhadores de uma cooperativa de serviços gerais; Diogo (2000) - trabalhadoras assalariadas do setor de limpeza; Morin et al. (2007) - jovens executivos; Moulin, Reis e Weinichi (2001) - trabalhadores do setor de rochas ornamentais; Teixeira (2009) - trabalhadoras do setor de vestuário. 
referem tanto à dimensão material da sobrevivência como às outras dimensões mais abstratas que também estão implicadas na constituição da subjetividade dos servidores. Dessa forma, optamos por organizá-los nas seguintes categorias: a) trabalho como provedor da vida material; b) trabalho como a (re)produtor de valores sociais; c) trabalho como operador de integração social; e d) trabalho como fonte de realização pessoal e sentido existencial.

\section{a) trabalho como provedor da vida material}

Assim como no estudo de Morin et al. (2007) sobre sentidos do trabalho para uma amostra que possuía bom nível de escolarização, os aspectos materiais associados aos sentidos do trabalho estão entre as primeiras referências feitas pelos participantes deste estudo. Assim se expressou um participante, indicando a garantia da sobrevivência como um dos primeiros atributos do trabalho: "Primeiro, é de onde tiro meu sustento". Mas a referência à dimensão material se estende para além da subsistência, como relata o entrevistado: "o trabalho é uma forma de sustento, né [...] de onde advêm meus recursos, né, pra eu poder adquirir meus bens, e poder fazer outras coisas, lazer, também".

Por se tratar de um grupo cuja remuneração é capaz de garantir mais do que as condições mínimas de sobrevivência, o trabalho é indicado como mediador que assegura tranquilidade e estabilidade à vida material, como expressou essa entrevistada:

[...] a gente tem casa própria, tem carro bom, tem, né... não passa dificuldade, meu esposo também é funcionário público, então, assim, é tranquilo. Por um lado, você pensa "ah, eu poderia parar de trabalhar e ficar em casa", mas aí também, o seu nível financeiro cai, então, você fica naquela...

Nesse ponto, é importante esclarecer que a satisfação com a remuneração é tema controverso no grupo investigado. Alguns avaliam que a remuneração é satisfatória, e, em geral, essa percepção emerge da comparação com outros segmentos da educação, como o setor privado ou mesmo a rede estadual de ensino, que historicamente enfrenta a desvalorização profissional dos trabalhadores da educação. Outros, a consideram insuficiente, como apontou um participante, ocupante de cargo de chefia, cuja gratificação, segundo sua percepção, é o que torna sua remuneração mais justa face ao volume de trabalho que vem se intensificando nos últimos anos.

De todo modo, fica claro que, para os participantes, o trabalho possui um sentido de estruturador da vida material e mediador de planos e realizações nessa esfera da existência. Trata-se de uma associação frequentemente identificada nos estudos sobre sentidos do trabalho (Coutinho et al., 2008; Dal Magro \& Coutinho, 2008; Moulin, Reis \& Weinichi, 2001; Nascimento \& Oliveira, 2013), e que traduz um significado comum à sociedade capitalista, uma vez que para a maioria das pessoas, trabalhar é a única possibilidade de subsistência (Coutinho et al., 2008).

\section{b) trabalho como a (re)produtor de valores sociais}

Outros sentidos atribuídos ao trabalho pelos servidores revelam sua estreita conexão com os valores socialmente produzidos, especialmente alguns que se associam à importância da liberdade e da autossuficiência, relacionadas à cultura individualista neoliberal, explicitando a dialética existente na produção social dos significados e sentidos do trabalho. A independência ou a autonomia são valores fortemente relacionados aos sentidos do trabalho expressos pelos 
participantes, a exemplo desses relatos: "[...]o trabalho é fundamental; ele confere independência, né, autonomia, me sinto... eh, valorizado"; e ainda:

[...]a partir do dia que eu comecei a estagiar, né, que eu tinha aquele dinheirinho, mesmo pouco, nunca mais eu pedi um centavo pra nada. [...] eu tenho pavor de pedir as coisas, então, independência financeira é uma coisa que eu prezo bastante.

Da mesma forma, "estar ocupado" conserva o valor da dignidade conferida ao homem através de uma atividade laboral. Ser reconhecido como alguém que trabalha, é um dos elementos que asseguram, no mundo capitalista, a valorização social (Dal Magro \& Coutinho, 2008; Matos, 1994; Moulin et al., 2001). Dentre os participantes deste estudo destacamos o seguinte relato:

Eu acho importante que todas as pessoas tenham realização profissional pra ter dignidade... pra se sentir digno... O trabalho traz a dignidade. Acho que seria isso. [...] além de ser uma ocupação por assim dizer também né, que não, não deixa ficar com o tempo ocioso né.

O serviço público, em comparação com o setor privado, oferece uma condição de maior estabilidade ao trabalhador, o que possibilita, em certa medida, maior planejamento e estruturação da vida. Essa "promessa" de estabilidade, face à crise mundial do desemprego e à precariedade do trabalho no mundo contemporâneo, tem motivado uma corrida para os concursos públicos nos últimos anos, como já apontaram Ribeiro e Mancebo (2009; 2013). Esse contexto, além de evidenciar os problemas concernentes ao mundo do trabalho, sugere, no mínimo, cautela diante das novas formas de organização do trabalho que, a exemplo do setor privado, vêm sendo implementadas, por vezes, indiscriminadamente, no serviço público, uma vez que esses novos modelos se caracterizam por flexibilização de jornadas, intensificação do trabalho, e precarização das relações de trabalho, aspectos que poderão colocar em risco as condições ora apontadas pelos servidores como fonte de sentido para o trabalho. Ou seja, a segurança comumente associada ao serviço público é instável, paradoxo que vem sendo enfrentado, de maneira invisível, pelos trabalhadores desse setor.

Para os entrevistados, o trabalho também se coloca como oportunidade para odesenvolvimento intelectual e aquisição de conhecimento, um "bem" de extremo valor na sociedade atual. Assim expressou um participante: "Aqui a gente o tempo inteiro é incentivado ao estudo, você tem que tá se atualizando, então, eh, um momento onde eu posso me sentir mais valorizado, onde eu posso me desenvolver intelectualmente".

\section{c) trabalho como operador de integração social}

Como observam Heloani e Capitão (2003), "se o homem passa a maior parte de seu tempo trabalhando, suas relações pessoais fora de casa deveriam ter um valor afetivo de extrema importância". Contudo, de acordo com estes autores, a configuração atual do mundo do trabalho tem dificultado o estabelecimento de laços de amizade e companheirismo, e mesmo diminuído o interesse pelas vivências e trocas coletivas (Heloani \& Capitão, 2003, p. 103).

Nesse aspecto, alguns participantes deste estudo consideram o trabalho como um potencial operador da integração social, do estabelecimento de vínculos afetivos e da troca de experiências, o que mostra seu papel fundamental para sua sociabilidade, como relata esse participante, que atua na Instituição há cerca de três décadas: 
[...] como eu entrei muito novo no serviço público, isso virou uma família pra mim, onde os meus amigos ficaram relacionados dentro do serviço público, entendeu, então, eu tenho uma afetividade muito grande com todos, e eu sinto muito falta disso aqui [...].

Contudo, as profundas mudanças pelas quais vem passando a Instituição, imersa no cenário mundial e nacional de transformações do trabalho, sinalizam outros tempos e outras formas de convivência que vêm se estabelecendo entre os servidores, como manifestou outro participante:

[...] vejo que se extinguiu, eu vou usar essa palavra, este espaço de convivência, se você quiser conviver com uma pessoa, tomar um café [...] conversar, você não tem uma sala pra pessoa conversar, coisa que já houve, então, você conversa em lugares públicos, não tem um lugar que você professor pode ficar separado, ou o técnico, do aluno [...] ter um momento seu, na verdade, fora isso, espaços de confraternização, eu também vejo pouco, né, no final de semana, atividades, eu vejo a questão de trazer a família, espaços que você possa estar com os filhos, etc. Então, eu sinto, né, essa impessoalidade, né, esse distanciamento [...]

No plano das relações entre servidores e usuários, o trabalho também adquire sentido através das interações humanas estabelecidas e das trocas de experiência, sinalizando sua importância para a constituição subjetiva do trabalhador, para além de sua dimensão técnica. Assim relatou um servidor:

[...] porque muitas vezes a gente não faz só o papel burocrático, mas a gente, no contato com o outro, acaba... ouvindo, né, também as dificuldades e, não diria nem aconselhando, mas trocando, né, experiências e... muitas vezes, eh, daquilo que a pessoa tá precisando, nesse momento pra tá conversando, pra tá se abrindo, então a gente acaba fazendo também esse papel, então isso faz bem pra gente né, como ser humano acho que é bom saber que você pode também ajudar o outro [...].

Esse aspecto do trabalho dos servidores públicos merece especial atenção, uma vez que as interações estabelecidas com os usuários constituem o elemento central de seu trabalho. Nesse sentido, a constatação de um incremento no quantitativo e na diversificação do público atendido, paralelo a um crescimento insuficiente da força de trabalho na Instituição pesquisada, geram preocupações com os desdobramentos, a médio e longo prazo, tanto para a qualidade dos serviços prestados como para a saúde e o bem-estar dos servidores.

Há, ainda, a dimensão ética referente às interações entre servidores e usuários, que, pari passu às transformações no mundo do trabalho, ou ainda, como uma de suas expressões, se coloca como objeto de análise aos estudiosos do trabalho, a exemplo de Chanlat (2002). O relato feito por um dos participantes ilustra esse aspecto de seu cotidiano laboral, caracterizado pela diversificação das relações estabelecidas entre ele, seus pares, os usuários, a chefia, e o público externo, que impõe, ao longo dos anos de trabalho, várias situações desafiadoras: cabia ao servidor prestar determinado atendimento aos alunos, os quais eram convocados em turmas, e atendidos individualmente ou em duplas, conforme a ordem de uma fila que se formou. A certa altura, uma aluna queixou-se de ter que esperar, alegando ser filha de determinada autoridade, o que, a seu ver, deveria conferir-lhe certa prerrogativa. Confrontado com a interpelação da aluna, o servidor respondeu-lhe:

[...] da porta da escola pra fora, você é filha [de fulano], aqui você é aluna [da Instituição], e eu não posso dar um tratamento diferenciado a você, então você tem que se acostumar com isso, porque você se inscreveu numa escola onde eu posso ser até processado por te dar um tratamento diferenciado [...]. 
Nesse mesmo sentido, Lancman et al. (2007) constataram, em uma pesquisa com agentes de trânsito, que o trabalho de intermediação com o público, leva a situações que exigem um manejo constante de habilidades intersubjetivas e põe o trabalhador face a questões éticas que lhe cabe arbitrar.

Certamente, a possibilidade que teve o servidor de responder ao usuário, como o fez, representa um fator positivo daquela organização do trabalho que concorre para a preservação da saúde e do bem-estar dos servidores. Contudo, não é desprezível, nos dias atuais, o incremento de situações nas quais, cada vez mais, o investimento psíquico e o autocontrole das emoções são exigidos (Pena \& Minayo-Gomez, 2010; Seligmann-Silva, 2011). Também nos cabe refletir sobre os efeitos, a médio e longo prazo, desses confrontos, para a saúde dos trabalhadores.

\section{d) trabalho como fonte de realização pessoal e sentido existencial}

À medida que permite ao indivíduo empregar e aprimorar suas habilidades, buscar sua superação, o trabalho possibilita o desenvolvimento do ser humano, e se define como fonte de satisfação e realização pessoal, como relatou esse participante:

Acho que o trabalho é importante pra... como uma forma de realização, você estuda, você se prepara, e depois você consegue colocar isso em prática, vivenciar o cotidiano, porque você consegue ajudar a resolver, né, é bem gratificante.

Nas expressões dos servidores, as práticas e relações vivenciadas no universo laboral se traduzem como fonte de sentido existencial. Entre aqueles há mais tempo na Instituição, ouvimos: "Trabalho, ele é uma coisa que já incorporou dentro de mim de uma tal maneira, que eu acho que na hora que eu tiver que parar mesmo de trabalhar, eu não sei como que vai ser..."; ou ainda: "[...] o trabalho tem um valor fundamental na minha vida, não consigo me ver sem trabalhar".

Reconhecendo a relevância que a vivência do trabalho possui para a imagem que o servidor público constrói de si mesmo, depreendemos que a imagem negativa socialmente construída dessa categoria profissional pode se constituir como uma fonte de sofrimento psíquico, e, consequentemente, gerar prejuízos à saúde mental desses profissionais. Essa compreensão se sustenta nos relatos dos participantes:

[...] eu já tive época de alguém falar assim "nossa, você nem parece servidor público, você trata a gente tão bem”. Porque realmente você vai a lugares, aí, que é um descaso danado, né. E isso me deixa assim, muito constrangido, porque é muito triste você ouvir isso, né.

[os alunos] acham que a gente não trabalha, que nosso setor [...] é um bando de gente que não faz nada; no nosso setor, eles acham que a gente não faz nada aqui; tanto é, que quando os bolsistas vêm trabalhar aqui falam "Nossa, não pensei que vocês trabalhassem tanto!" Falei assim, "eh, agora vocês passam pros colegas de vocês, pra vocês verem o que é que acontece, que aqui a gente trabalha, não é moleza tá" [...].

Matos (1994), ao discutir a alienação no serviço público, aborda a ambivalência dos sentidos relacionados ao trabalho entre esses trabalhadores - apesar dos significados objetivos, relacionados à estruturação da vida material, ou de sua importância simbólica, ligada à valorização social do "trabalhar" na sociedade moderna, os servidores têm de lidar com a falta de reconhecimento e a 
desvalorização social do serviço público, que como já apontaram Ribeiro e Mancebo (2013), se estendem também aos servidores.

Compreendemos que as expressões dos servidores são um indicativo da centralidade do trabalho em suas vidas, a despeito de todas as transformações ocorridas no mundo produtivo. Parece-nos, com base nesses resultados, que para esses sujeitos, o trabalho continua a exercer um papel de destaque na (re)construção de si e do mundo a sua volta. A respeito disso, Moulin et al. (2001, p. 36) salientam:

O trabalho, assim, assume um valor como prática social que faz com que o sujeito se sinta participante e também responsável pela transformação da realidade. Nesse sentido, o trabalho contribui para se conceber o homem como produtor do mundo e de si mesmo. Consideramos essa dimensão do trabalho fundamental por colocar em questão a capacidade do homem de se ver enquanto inserido no processo de construção de novos modos de ser e de viver, baseados na percepção de suas potencialidades e limitações.

Dessa forma, muito além da satisfação de necessidades básicas, o trabalho pode ser concebido como fonte de sentido existencial para muitos que dele vivem. Como relatou um participante, "[...] pra mim, trabalho é vida".

Nos resultados apresentados identificamos algumas aproximações com estudos já realizados sobre a temática sentidos do trabalho. Percebemos que os sentidos atribuídos ao trabalho pelos sujeitos desta pesquisa trazem à tona aspectos também identificados por Morin et al. (2007), como satisfação pessoal, independência, sobrevivência, crescimento e aprendizagem, identidade, utilidade, relacionamento, inserção social, e contribuição social.

Também observamos algumas aproximações com os resultados encontrados por Nascimento e Oliveira (2013). Embora não tenhamos focalizado as diferenças geracionais entre os servidores entrevistados, percebemos uma frequência maior de respostas que sugerem uma perspectiva atravessada por uma lógica instrumental do trabalho entre os servidores que ingressaram mais recentemente na Instituição, e, entre os servidores mais antigos, sentidos que revelam a valorização de aspectos mais subjetivos ligados ao trabalho.

\section{Considerações finais}

A análise dos sentidos atribuídos ao trabalho por trabalhadores de uma instituição pública federal de ensino contribui para dimensionar a importância dessa atividade na vida desses sujeitos. As significações foram preponderantemente positivas, porém não destituídas de conflitos e desafios próprios de uma atividade e de uma instituição cujos objetivos e alcance encontram-se em intensa transformação. Também revelam que o mundo do trabalho dos servidores públicos mostra-se cada vez mais permeado de incertezas - a despeito da segurança promovida por esse tipo de serviço em termos da estabilidade no emprego.

A multiplicidade de sentidos, por vezes, paradoxais, assim como em outros estudos, inclui a associação entre trabalho, planejamento e estruturação da vida material, indicando o papel central do trabalho nessa esfera da existência.

Outra conexão muito significativa que emergiu dos relatos dos participantes foi entre trabalho e a (re) produção de valores sociais, tais como autonomia, independência, dignidade conquistada através de uma ocupação produtiva, oportunidade de aquisição de conhecimento, explicitando a dialética estabelecida entre os significados do trabalho e os valores históricos e socialmente constituídos, que permeiam os processos de subjetivação dos trabalhadores e a construção de sua identidade. 
A valorização da aquisição de conhecimento presente no sentido atribuído ao trabalho pelos servidores também suscita a hipótese de uma singularidade ou de uma maior frequência desse tipo de sentido entre trabalhadores que atuam no serviço público ligado ao ensino, em relação a outras áreas do serviço público. Desse modo, seriam oportunos estudos comparativos dessa temática entre diferentes áreas do setor público.

O convívio no ambiente de trabalho, tanto entre servidores como entre eles e o público atendido, confere um forte sentido ao trabalho como operador de integração social e de trocas de experiências. Entre os entrevistados, constatou-se tanto a percepção da importância das relações intersubjetivas no ambiente de trabalho como fonte de afetividade, como o sentimento de diminuição das oportunidades de convívio entre pares, resultante dos novos arranjos da organização do trabalho. Paradoxalmente, decorrente do tipo de trabalho (serviços), e das mudanças institucionais que ampliaram e diversificaram a clientela, trata-se de um trabalho intenso em interações humanas, que desafia constantemente os servidores em suas habilidades intersubjetivas.

Outro sentido evidenciado pelos relatos dos entrevistados remete ao sentimento de realização pessoal alcançada por meio da aplicação de habilidades e potencialidades construídas pelos servidores ao longo da vida. Também se constata que o trabalho participa de modo crucial nos processos identitários, contribuindo tanto na reafirmação "de quem se é", como suscitando desconforto e sofrimento no confronto com a imagem negativa socialmente atribuída aos servidores públicos.

Além de dar visibilidade ao gosto e desgosto de ser servidor público, tais elementos também se mostram significativos nas possibilidades de intervenção da Psicologia, em uma perspectiva de promoção da saúde desses trabalhadores, especialmente em um contexto de implantação de novos modos de organização do trabalho.

Compreendemos que há um longo caminho pela frente para os estudos sobre trabalho e saúde dos servidores públicos, aos quais nos parece relevante aprofundar a investigação da relação que se estabelece entre os novos modos de gestão que vêm sendo adotados (que no caso do setor público, incluem uma mudança em sua própria ética), as mudanças na sociabilidade no ambiente laboral, e os desdobramentos desse contexto para a saúde e a vida desses trabalhadores.

\section{Referências}

Antunes, R., \& Alves, G. (2004). As mutações no mundo do trabalho na era da mundialização do capital. Educação e Sociedade, 25 (87), 335-351.

Assunção, A. A., \& Lima, F. P. A. (2010). Aproximações da ergonomia ao estudo das exigências afetivas da tarefa. In D. M. R. Glina \& L. E. Rocha (Orgs.), Saúde Mental no Trabalho: da teoria à prática (pp. 210-228). São Paulo: Roca.

Borsoi, I. C. F. (2007). Da relação entre trabalho e saúde à relação entre trabalho e saúde mental. Psicologia E̊ Sociedade, 19 (ed. esp.1), 103-111.

Chanlat, J. F. (2002). O gerencialismo e a ética do bem-comum: a questão da motivação para o trabalho nos serviços públicos. In Anais de VII Congreso Internacional del CLAD sobre la Reforma del Estado y de la Administración Pública, (pp. 8-11). Lisboa: [s. n.].

Coutinho, M. C., Diogo, M. F., \& Joaquim, E. P. (2008). Sentidos do trabalho e saber tácito: estudo de caso em universidade pública. PSIC - Revista de Psicologia da Vetor Editora, 9 (1), 99-108.

Dal Magro, M. L. P., \& Coutinho, M.C. (2008). Os sentidos do trabalho para sujeitos inseridos em "empreendimentos solidários". Psicologia em estudo, 13 (4), 703-711.

Dejours, C. (2008). Addendum: da psicopatologia à psicodinâmica do trabalho. In S. Lancman \& L. I. Sznelwar (Orgs.), Christophe Dejours: da psicopatologia à psicodinâmica do trabalho (pp. 49-105). Brasília: Paralelo15. 
Deslandes, S. F. (2010). O projeto de pesquisa como exercício científico e artesanato intelectual. In M. C. S. Minayo (Org.), Pesquisa social: teoria, método e criatividade (pp.31-60). Petrópolis: Vozes.

Diogo, M. F. (2007). Os sentidos do trabalho de limpeza e conservação. Psicologia em estudo, 12 (3), 483-492.

Ferri, M. R. (2003). Os saberes do funcionário público na administração municipal: um estudo de caso em um município de pequeno porte. Dissertação de Mestrado, Programa de Pós-Graduação em Administração, Universidade Estadual de Londrina/Universidade Estadual de Maringá, Maringá.

França, B. H. (1993). O Barnabé: consciência política do pequeno funcionário público. São Paulo: Cortez.

Franco, T. (2004). A centralidade do trabalho na visão da psicodinâmica de Dejours. Caderno CRH, 17 (41), 309-321.

Gomes, R. (2010). Análise e interpretação de dados de pesquisa qualitativa. In M. C. S Minayo (Org.). Pesquisa social: teoria, método e criatividade (pp. 79-108). Petrópolis: Vozes.

Gondar, J. O. (1989). O trabalho como objeto histórico. Cadernos do NUPSO, 2 (3), 20-32.

Heloani, J. R., \& Capitão, C. G. (2003). Saúde mental e psicologia do trabalho. São Paulo em Perspectiva, 17 (2), 102-108.

Krawulski, E. (1998). A orientação profissional e o significado do trabalho. Revista da ABOP, 2 (1), 5-19.

Lacaz, F. A. C., \& Minayo-Gomez, C. (2005). Saúde do trabalhador: novas-velhas questões. Ciência Ė Saúde Coletiva, 10 (4), 797-807.

Lancman, S., Sznelwar, L. I., Uchida, S., \& Tuacek, T. A. (2007). O trabalho na rua e a exposição à violência no trabalho: um estudo com agentes de trânsito. Interface - Comunic., Saúde, Educ., 11 (21), 79-92.

Martins, S. A. C., \& Krawulski, E. (2012). Trabalho em integração com a vida: trajetórias de trabalhadores da atenção básica à saúde e a construção de sua identidade profissional. Cadernos de Psicologia Social do Trabalho, 15 (1), 115-134.

Marx, K. (1996). O Capital: crítica da economia política (Coleção Os Economistas). São Paulo: Nova Cultural.

Matos, A. G. (1994). Alienação no serviço público. Psicologia: Ciência e Profissão, 14 (1-3), 28-33.

Meirelles, D. S. (2006). O conceito de serviço. Revista de Economia Política, São Paulo, 26 (1), 119-136.

Minayo, M. C. S. (2010). O desafio da pesquisa social. In M. C. S. Minayo (Org.), Pesquisa social: teoria, método e criatividade (9-29). Petrópolis: Vozes.

Morin, E., Tonelli, M. J., \& Pliopas, A. L. V. (2007). O trabalho e seus sentidos. Psicologia em Sociedade, 19 (esp.), 47-56.

Moulin, M. G. B., Reis C. T., \& Weinichi, G. H. (2001). No meio do caminho havia uma pedra: organização do trabalho e saúde no processo de extração e beneficiamento de mármore. In C. Kiefer, I. Fagá \& M. R. Sampaio (Orgs.), Trabalho, Educação e Saúde: um mosaico em múltiplos tons (pp. 221-240). Vitória: Fundacentro.

Nascimento, T. A. C., \& Oliveira, S. R. (2013). Os sentidos do trabalho no serviço público: uma perspectiva geracional. In XXXVII Encontro da ANPAD, Rio de Janeiro/RJ. Associação Nacional de Pós-Graduação e Pesquisa em Administração.

Navarro, V. L., \& Padilha, V. (2007). Dilemas do trabalho no capitalismo contemporâneo. Psicologia Eु Sociedade, 19 (ed. esp.1), 14-20.

Pena, P. G. L., \& Minayo-Gomez, C. (2010). Premissas para a compreensão da saúde dos trabalhadores no setor serviço. Saúde EO Sociedade, 19 (2), 371-383.

Pinto, G. A. (2007). A organização do trabalho no século 20 - Taylorismo, fordismo e toyotismo. São Paulo: Expressão Popular.

Ribeiro, C. V. S. \& Mancebo, D. (2009). Concurso público, uma alternativa sensata frente às turbulências do mundo do trabalho? Trabalho Ë Educação, 18 (1), 145-156.

Ribeiro, C. V. S., \& Mancebo, D. (2013). O servidor público no mundo do trabalho do século XXI. Psicologia: Ciência e Profissão, 33 (1), 192-207.

Seligmann-Silva, E. (2011). Trabalho e desgaste mental: o direito de ser dono de si mesmo. São Paulo: Cortez.

Teixeira, C. M. (2009). As mulheres no mundo do trabalho: ação das mulheres, no setor fabril, para a ocupação e democratização dos espaços público e privado. Psicologia: Teoria e Pesquisa, 25 (2), 237-244.

Tolfo, S. R., Coutinho, M. C., Baasch, D., \& Cugnier, J. S. (2011). Sentidos y significados del trabajo: un análisis con base en diferentes perspectivas teórico-epistemológicas en Psicología. Universitas Psychologica, 10 (1), 175-188. 
Tolfo, S. R., \& Piccinini, V. (2007). Sentidos e significados do trabalho: explorando conceitos, variáveis e estudos empíricos brasileiros. Psicologia Eु Sociedade, 19 (ed. esp.1), 38-46.

Vygotsky, L. (1995). Obras Escogidas - Historia del desarrollo de las funciones psíquicas superiores. Madri: Visor.

Endereço para correspondência

sheilapsi@gmail.com

mgbmoulin@gmail.com
Recebido em: 02/04/2013

Revisado em: 30/01/2014

Aprovado em: 13/02/2014 